\title{
Comparative suitability of two culture media to the in vitro growth of embryos of three coconut types
}

\author{
Tessie C. Nuñez \\ National Coconut Research Center-Visayas, Visayas State University (formerly \\ Leyte State University), Visca, Baybay City, Leyte 6521-A, Philippines
}

\section{ABSTRACT}

Using a suitable medium for specific plant genotype greatly improves the efficiency of the in vitro culture method. The Visayas State University (VSU)-based National Coconut Research Center -Visayas (NCRC-V) evaluated the comparative suitability of the COGENT medium and VSU-modified Y3 (mY3) as in vitro culture media for coconut embryos using Albuera Dwarf (ALD), Baybay Tall (BAYT), and the VSUdeveloped Coconifio x Makapuno (VMAC1) hybrid. These two media differ in vitamin components, iron concentration and state during the first two stages of culture, namely germination and first subculture.

Results showed that $\mathrm{mY} 3$ was more suitable for the in vitro germination and development of the coconut embryos than the COGENT medium. Significantly higher germination rates were observed in BAYT, ALD, and VMACl cultured in the semi-solid mY3 than those in the liquid COGENT medium from the first week until the fourth week of initial culture. Germination rates of $100 \%, 85.8 \%$ and $84.5 \%$ were obtained from CÑO $x$ MAC, ALD, and BAYT, respectively. Furthermore, significantly higher percentages of germinating embryos with developing shoot and root were observed in the semi-solid $\mathrm{mY} 3$ than in the liquid COGENT. Likewise, better growth of plantlets in liquid $\mathrm{mY} 3$ was noted during the fourth and fifth months of culture.

Among coconut types, VMACl had the highest germination rates in the two media and the best growth in $\mathrm{mY3}$. BAYT had better growth in the COGENT medium while ALD had better shoot development in $\mathrm{mY} 3$

Keywords: coconut, Cocos nucifera L., coconut embryo culture, in vitro culture media, in vitro growtl.

Correspondence: T. C. Nuñez Address: National Coconut Research Center-Visayas, Visayas State University, Baybay City, Levte. 6521-A, Philippines. Tel. No. (053) 335-2628

DOI: $10.32945 /$ atr2925.2007 


\section{INTRODUCTION}

Coconut (Cocos nucifera $\mathrm{L}$.) is reproduced mainly by seed. Due to the large size of its seed, coconut germplasm collection and exchange is costly and laborious. Hence, the embryo culture technology is considered an efficient, safe, and practical tool for coconut germplasm collection and exchange since it reduces problems in handling and transport of coconut genetic materials. For germplasm exchange, the FAO/IBPGR Technical Guidelines for the Safe Movement of Coconut Germplasm recommends the distribution of coconut as zygotic embryos in vitro to reduce chances of introducing diseased material into disease-free areas (Engelmann, 1997; Frison et al., 1993). In addition, embryo rescue through in vitro culture is the only way to grow the homozygous makapuno $(\mathrm{mm})$ palms.

Makapuno is the most popular and economically important softendospermed coconut in the Philippines. However, its production is very limited due primarily to very limited planting materials. Embryos of this aberrant form of coconut do not germinate in the nut due to perishable meat and lack of the enzyme necessary for the mobilization of galactomannans that contribute to germination of their embryos (Rillo, 1997; Samonte, et al., 1989) so, embryo rescue and in vitro culture must be done.

In the Visayas State University (VSU)-based National Coconut Research Center-Visayas (NCRC-V), breeding work on soft-endospermed makapuno requires the use of the embryo culture technology to grow the homozygous makapuno palms from dwarf $x$ makapuno hybrids. VSU modified $Y 3$ medium (mY3) (Nuñez and de Paz, 1996) is used throughout the culture period with a seedling recovery rate of at least $70 \%$. Considering that different plant genotypes may vary in their responses to different in vitro culture medium formulations and in an attempt to improve seedling recovery rate, VSU studied the possibility of using an improved in vitro culture medium which was developed by the International Coconut Genetic Resources Network's (COGENT) in collaboration with a number of coconut tissue culturists from France, Vietnam, and the Philippines (Rillo, 2000) for its hybrid makapuno. A ten-month study funded by COGENT was conducted to assess the comparative suitability of the COGENT medium and $\mathrm{mY} 3$ on the growth of embryos of three coconut types from the VSU germplasm as well as, to determine genotypic differences in culture responses of the different coconut types to the culture media. 


\section{Materials and Methods}

\section{Coconut materials}

Three types of coconut namely: Albuera Dwarf(ALD), Baybay Tall (BAYT) and the homozygous makapuno $(\mathrm{mm})$ from Coconiño $\mathrm{x}$ Makapuno (VMAC1) hybrid were used as embryo donors. While ALD and BAYT are indigenous to Leyte, Coconiño is a small-seeded self-pollinated dwarf coconut from the University of the Philippines at Los Baños (UPLB). Makapuno pollen used in the development of VMAC1 was also obtained from UPLB but the controlled hybridization work was done in VSU. The embryos were obtained from 10-11 month old nuts of the three coconut types.

\section{Culture media}

Two culture media were used in the study; the COGENT medium and the modified Y3 (mY3). The COGENT medium has Y3 (Euwens, 1978) macro and micro nutrients, higher FeEDTA concentration of $4.17 \mathrm{~g}$ per liter of medium and the combined vitamins used by UPLB and the Philippine Coconut Authority (PCA)-Albay Research Center (Table 1). Modified Y3 (mY3) also contains the macro and micro components of $Y 3$ but the vitamin components were modified by VSU researchers to suit the requirements of the makapuno hybrid embryos. VSU uses the semi-solid form of the $\mathrm{mY} 3$ medium for germination of the hybrid makapuno embryos while other laboratories such as those in UPLB and PCA use the liquid form of COGENT. Fifteen milliliters $(\mathrm{ml})$ of each medium was dispensed to $150 \mathrm{~mm} \times 55 \mathrm{~mm}$ test tube for the initial culture. For the final culture, $70 \mathrm{ml}$ of $\mathrm{mY} 3$ and $80 \mathrm{ml}$ of COGENT were used. Media preparation was done three days before inoculation of embryos and at least one day before each subculture.

\section{Explant preparation, culture and data gathering}

Following the procedure established by PCA's Makapuno Laboratory (Rillo, 2000), coconut embryos were extracted from the makapuno nuts in meat cylinders. Meat cylinders were washed with tap water and surface sterilized using full strength commercial bleach, rinsed thrice with sterile distilled 
Table I. Components (g per liter) of COGENT and $\mathrm{mY} 3$ in vitro culture media for coconut embryos

\begin{tabular}{|c|c|c|}
\hline Component & COGENT & $\mathrm{mY3}$ \\
\hline \multicolumn{3}{|l|}{ Macronutrients: } \\
\hline potassium nitrate & 20.20 & 20.20 \\
\hline potassium chloride & 14.92 & 14.92 \\
\hline ammonium chloride & 535 & 5.35 \\
\hline sodium phosphate monobasic & 3.12 & 3.12 \\
\hline calcium chloride dihydrate & 2.94 & 2.94 \\
\hline magnesium sulphate heptahydrate & 2.47 & 2.47 \\
\hline \multicolumn{3}{|l|}{ Micronutrients: } \\
\hline manganese sulphate tetrahydrate & 1.12 & 1.12 \\
\hline potassium iodide & 0.83 & 0.83 \\
\hline zinc sulphate heptahydrate & 0.72 & 0.72 \\
\hline boric acid & 031 & 0.31 \\
\hline copper sulphate pentahydrate & 0.025 & 0.025 \\
\hline sodium molybdate dehydrate & 0.024 & 0.024 \\
\hline cobalt chloride hexahydrate & 0.024 & 0.024 \\
\hline nickel chloride hexahydrate & 0.0024 & 0.0024 \\
\hline \multicolumn{3}{|l|}{ Iron Solution } \\
\hline sodium EDTA dihydrate & 4.17 & 3.19 \\
\hline Iron sulphate heptahydrate & 1.39 & 1.39 \\
\hline \multicolumn{3}{|l|}{ Vitamin Solution } \\
\hline Thiamine $\mathrm{HCl}$ & 0.005 & 0.005 \\
\hline Pyridoxine $\mathrm{HCl}$ & 0.005 & 0.005 \\
\hline Nicotinic acid & 0.005 & 0.005 \\
\hline Ca-D Panthothenate & 0.005 & - \\
\hline Biotin & 0.005 & - \\
\hline Folic acid & 0.005 & - \\
\hline Glycine & 0.100 & - \\
\hline L-arginine & - & 1.00 \\
\hline L-asparagine & - & 8.81 \\
\hline L-glutamine & - & 10.11 \\
\hline Sugar (Table grade) & 60 & 45 \\
\hline Activated charcoal & 1 & 1 \\
\hline Agar & 7 & 7 \\
\hline $\mathrm{pH}$ & 5.6 & 5.6 \\
\hline \multicolumn{3}{|l|}{ State of the medium } \\
\hline Germination & liquid & semi-solid \\
\hline Ist subculture & solid & liquid \\
\hline 2nd subculture & liquid & liquid \\
\hline
\end{tabular}


water, and inoculated singly on fresh germination medium in test tubes. Forty embryos of each coconut type were used per medium per replication. Three replications were set up.

Inoculated embryos were kept in an air-conditioned incubation room in dark condition. Germination of embryos was monitored weekly. Emergence of either shoot or root primordium of each embryo was considered the start of germination. Length of shoots and/or roots was measured weekly during the first month of culture. After 1 to $1 \frac{1}{2}$ months in initial culture, germinated embryos with one inch-long shoots were subcultured on fresh media. During the first subculture, roots were cut to approximately one half inch for easy handling and enhancement of the growth of new roots. The number of developing roots was determined at two and three months in culture since it is important in the survival of the seedlings during potting as observed by NCRC$V$ researchers. Development of sufficient lateral roots is therefore a requirement before in vitro grown seedlings can be transferred from the laboratory to greenhouse conditions (del Rosario, 1997).

\section{RESULTS AND DISCUSSION}

In vitro germination of embryos from three coconut types using two culture media

Initial emergence of the shoot was observed as early as one week after inoculation in both semi-solid $\mathrm{mY} 3$ and the liquid COGENT media. However, higher germination rates were observed from coconut embryos cultured in the semi-solid $\mathrm{mY} 3$ than in liquid COGENT medium with BAYT, ALD and VMAC1 having $34.3 \%, 38.0 \%$ and $39.9 \%$ germination, respectively, in the solid $\mathrm{mY} 3$ one week after inoculation (Fig.1). In the liquid COGENT medium, they had $8.93 \%, 24.2 \%$ and $16.1 \%$ germination, respectively. Germination percentages increased rapidly during the second week but slowed down during the third week until the fourth week of observation. After four weeks in culture, BAYT, ALD and VMAC1 had germination percentages of 84.5, 85.8 and 100 , respectively.

Among the three coconut types, VMAC1 had the highest germination 


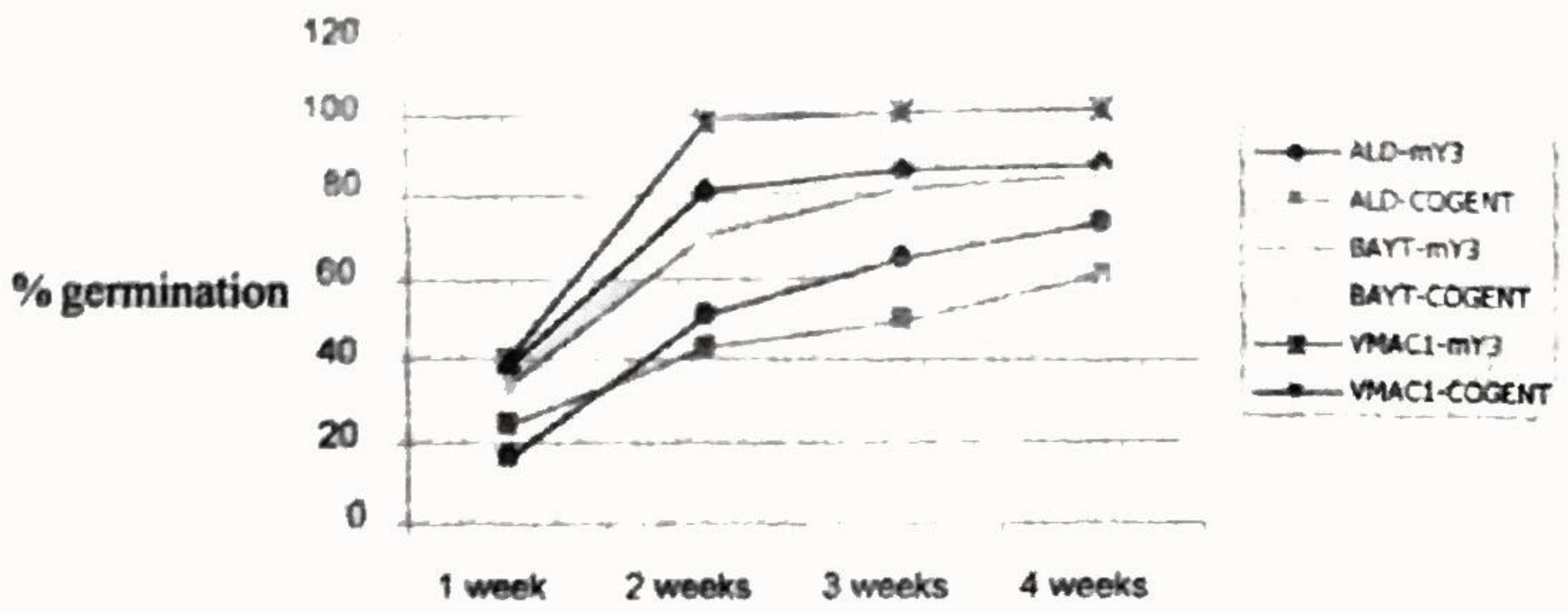

Figure 1. Germination rates of embryos of 3 coconut types in two germination media during the first four weeks in culture

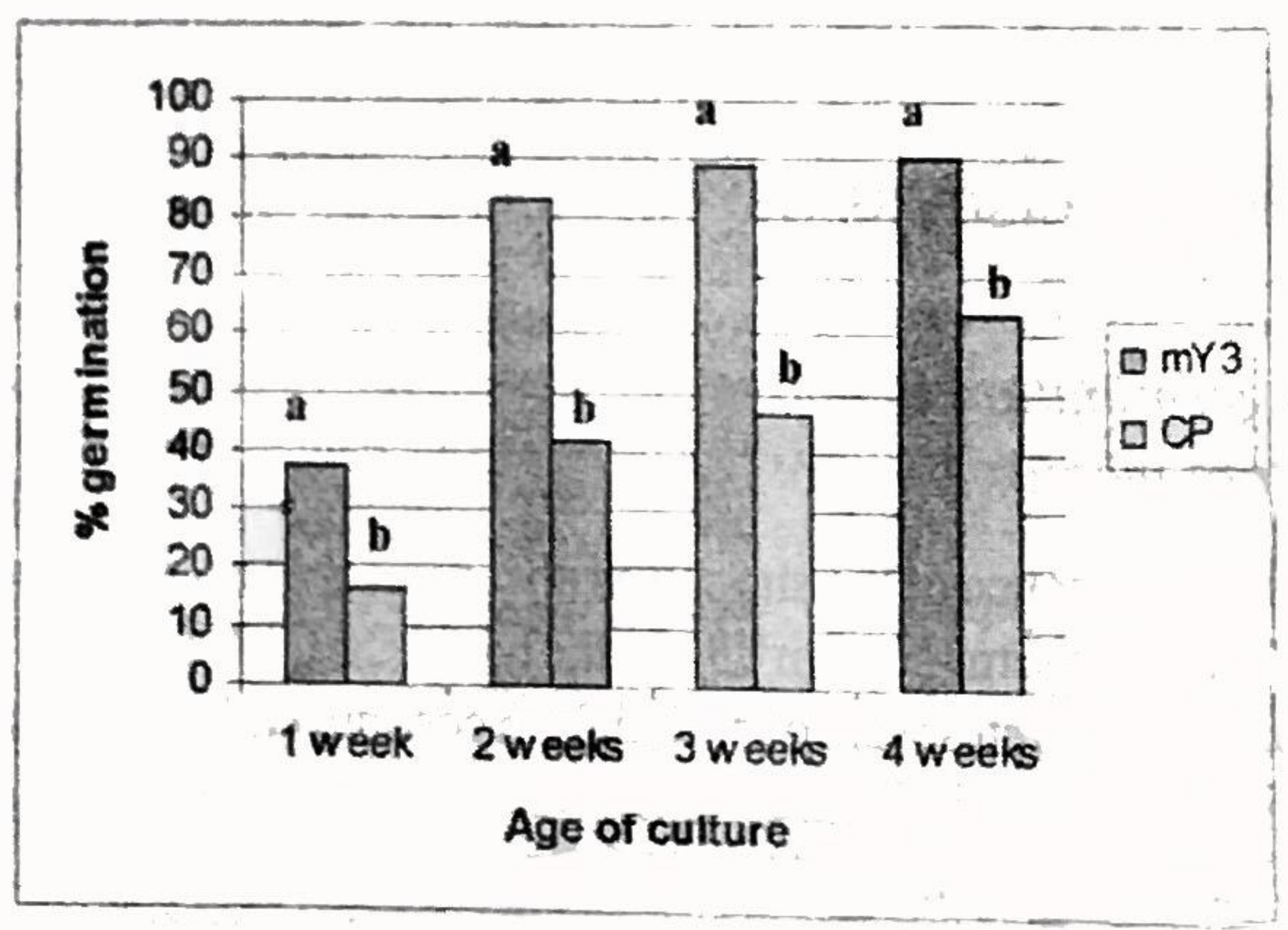

Figure 2. Mean germination percentages of embryos in two germination media across coconut types 
rates in the two media followed by ALD. BAYT had the least germination percentages in both media. However, differences in their germination rates during the fourth week of culture were not significant.

Across coconut types, mean germination percentages were significantly higher in semi-solid $\mathrm{mY} 3$ than in liquid COGENT from the first week of culture until the fourth week when mean germination reached $90.0 \%$ in the former and $63.6 \%$ in the latter (Fig.2). This result is in line with the findings of Centro de Investigacion Cientifica de Yucatan (CICY) in Merida, Mexico where higher germination of coconut embryos was observed when gelling agent was added to the germination medium and embryos were inoculated in vertical position with the plumule axis oriented upward (IPGRI, 1998).

The significantly higher germination percentages of the coconut embryos in semi-solid $\mathrm{mY} 3$ during the first 4 weeks of culture could not be attributed to a specific factor since the two media differed in vitamin components; iron concentration and state or phase. However, a study on the effect of embryo positions on embryo germination showed that the vertical position with the plumule end oriented upwards was the best position among other treatments which included horizontal position and vertical position with the plumule axis downwards (IPGRI, 1998). The semi-solid mY3 had an obvious advantage in keeping the embryo in upright position. Developing shoots of germinating embryos in the solid medium were observed to be oriented upward while roots were naturally growing downward (Figs. 3 and 4). In the liquid COGENT, there were three orientations of the growing embryos; shoots were more often oriented horizontally while others were oriented upward or downward. Horizontal orientation was a problem since shoot development was almost always restricted by test tube walls as early as two weeks after inoculation. The embryos enlarged faster in the liquid COGENT even prior to germination. Subculturing to fresh medium must be done before the cultures reach one month to prevent difficulty in taking out the germinating or enlarged embryo from the culture vessel. Downward orientation also posed a problem during transfer since both the shoot and developing root were oriented upward. One possible solution to keep the embryos in the upright position in the liquid germinating medium is the use of paper bridges. However, this has not been tried in this study. 


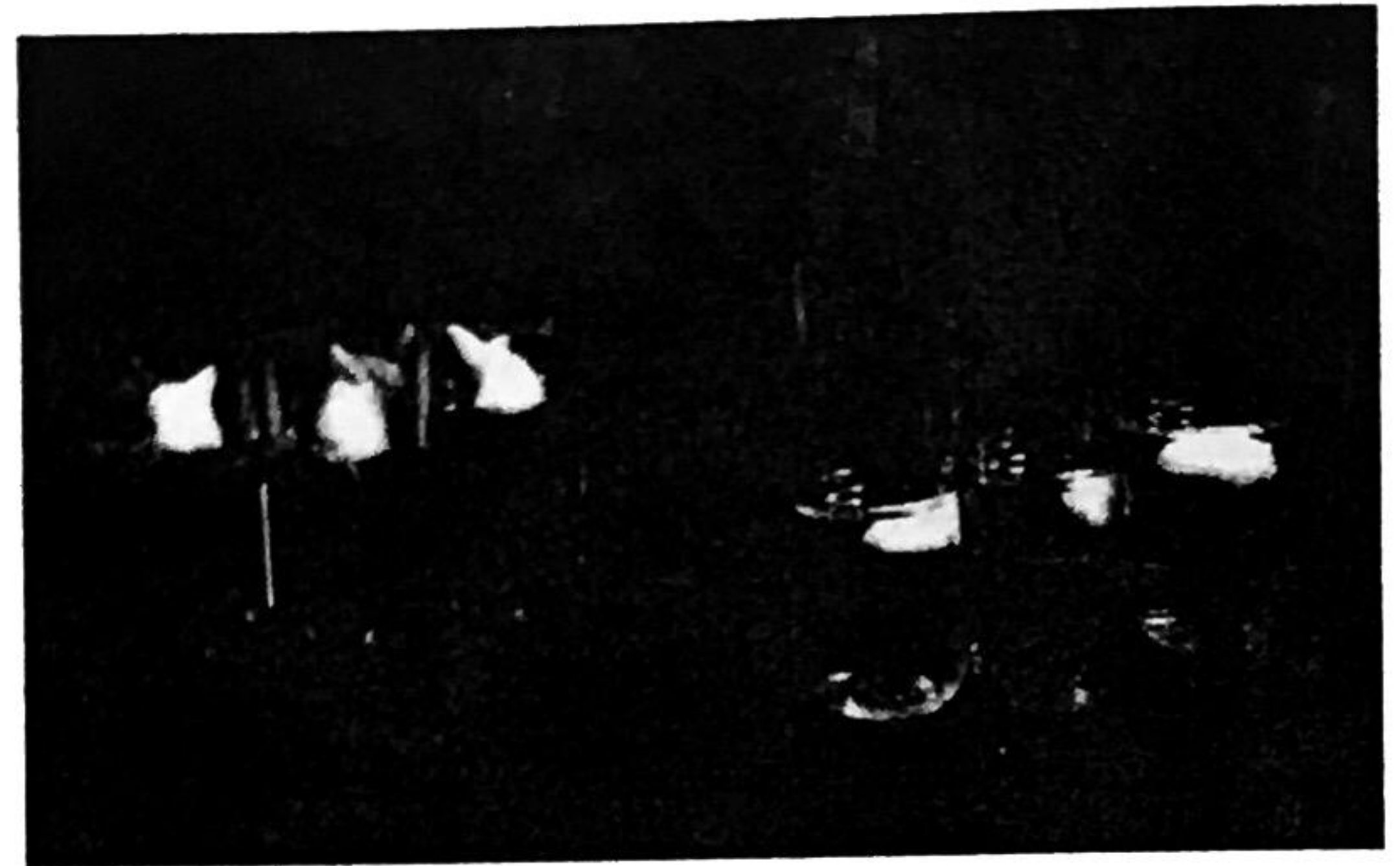

Figure 3. CÑ $\times$ MAC embryos in $\mathrm{mY} 3$ (left) and $\mathrm{CP}$ (right) germinating media one month after inoculation

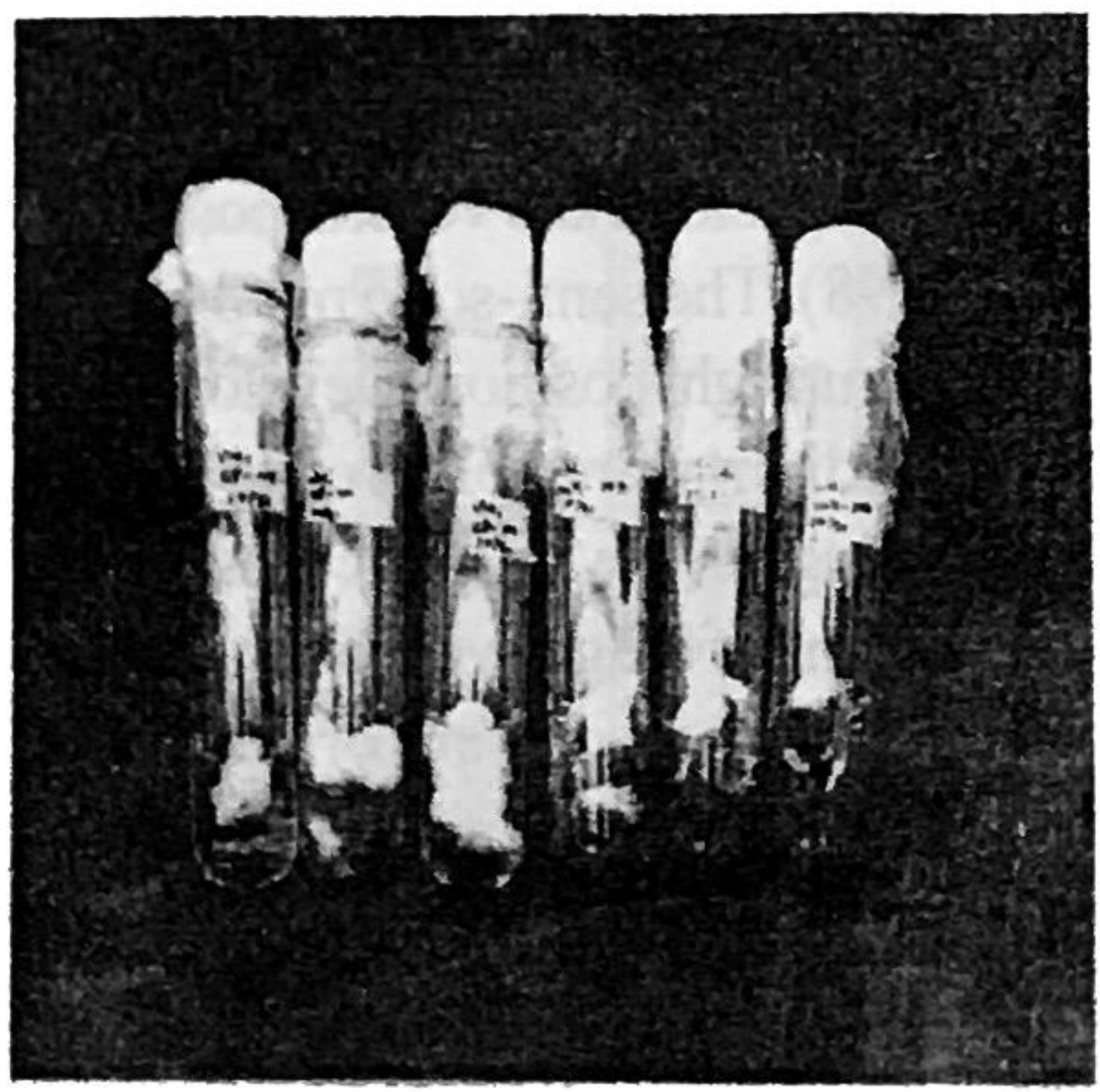

Figure 4. CÑO $\times$ MAC germinated embryos in $\mathrm{CP}$ and $\mathrm{mY} 3$ two months after inoculation 


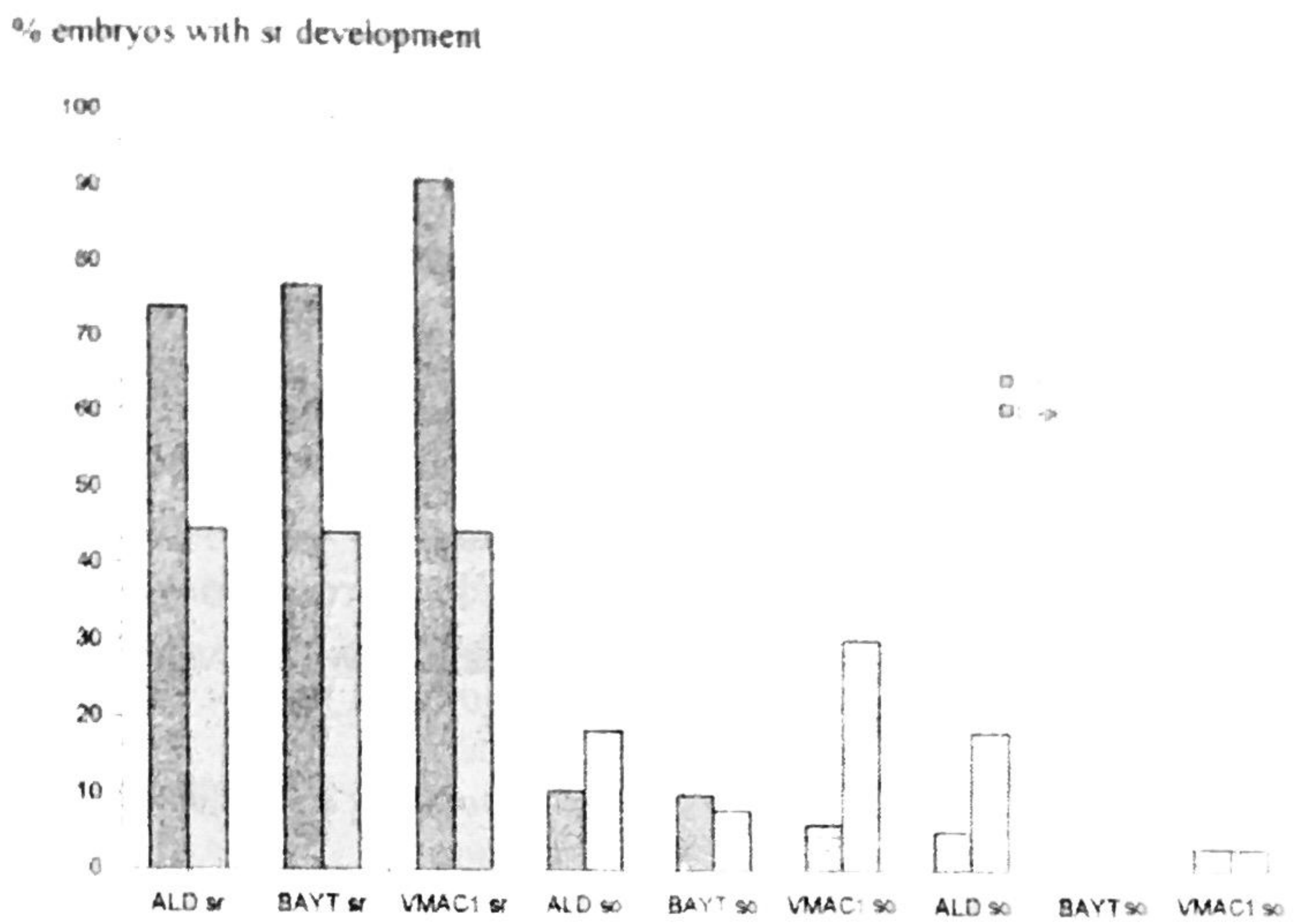

Figure 5. Shoot and root (sr) development of three coconut types in two in vitro culture media at one month after inoculation

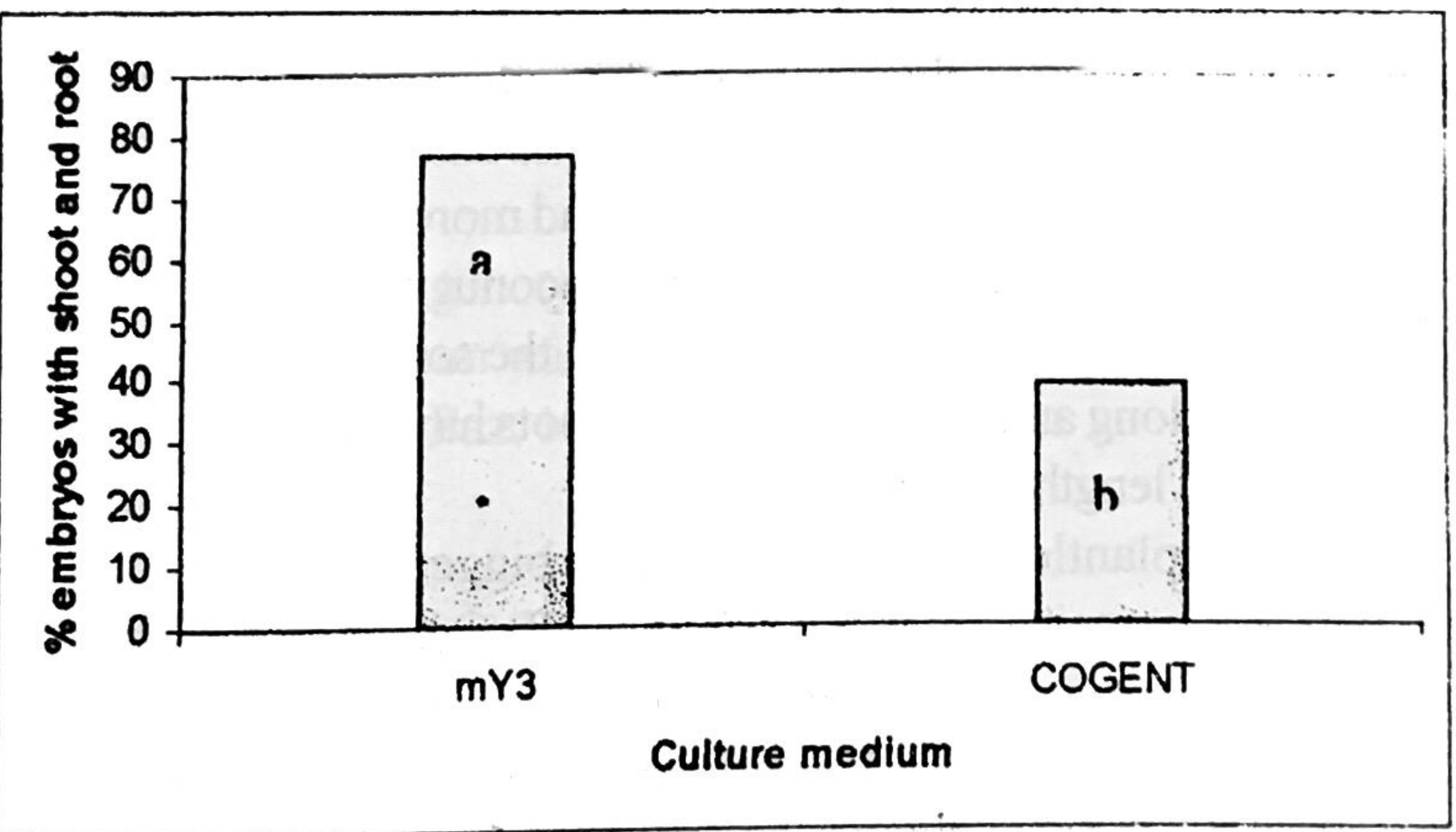

Figure 6. Mean percentages of embryos with developed shoot and root at one month in two culture media 


\section{Shoot and root emergence during germination}

The development of both shoot and root is desired in in vitro cultured coconut embryos. In this study, the three coconut types showed higher percentage of germinated embryos having developed shoot and root (sr) after one month of inoculation on the semi-solid $\mathrm{mY} 3$ than in the liquid COGENT (Fig. 5). There were few embryos that developed only shoots in the liquid COGENT (so) except for VMACl where $39.6 \%$ of cultured embryos developed shoots without roots. Fewer embryos in $\mathrm{mY} 3$ developed roots only (ro); $18 \%$ in ALD and $1.0 \%$ in VMAC1. Across coconut types, significantly higher percentage of one-month old plantlets with developed shoots and roots was observed in $\mathrm{mY} 3$ (Figure 6).

\section{Development of plantlets}

One-month old plantlets of BAYT and VMAC1 more often developed longer shoots in the semi-solid mY3 than in COGENT. The opposite trend was observed in ALD (Tạble 2). The makapuno hybrid VMAC1 had longer roots in the solid $\mathrm{mY3}$. Root development of ALD and BAYT however, did not show a consistent trend. Root length was not measured after the first month since the primary root of a germinated embryo was cut prior to transfer to fresh medium during the first subculture. Number of new roots was then monitored instead of root length during the second and third months of culture. About $50 \%$ of the coconut plantlets in $\mathrm{mY} 3$ had more secondary roots. After five months in culture, plantlets of the three coconut types in the liquid $\mathrm{mY} 3$ almost always had longer shoots than those in the solid COGENT medium. Roots were very long and numerous tertiary roots have developed so data on their number and length were not gathered.

Moreover, plantlets grown in $\mathrm{mY} 3$ had bigger leaves. They also had better root development than those in COGENT. Generally more secondary roots and root hairs were developed in plantlets cultured in $\mathrm{mY}$, which had lower iron concentration than COGENT medium. Iron deficiency in the roots is known to decrease root elongation but root diameter and amount of root hairs are increased (DUCHEFA, 1998). Since root hairs are active in water and nutrient absorption, seedlings with more root hairs will have better survival when potted.

Based on shoot and root development, BAYT apparently had the best 
Table 2. Mean shoot and root lengths $(\mathrm{mm}) /$ root number of developing plantlets of three coconut types cultured in vitro in COGENT and $\mathrm{mY} 3$ media

\begin{tabular}{|c|c|c|c|c|c|}
\hline $\begin{array}{l}\text { Age } \\
\text { (Month) }\end{array}$ & $\begin{array}{l}\text { Culture } \\
\text { Medium }\end{array}$ & $\begin{array}{l}\text { Growing } \\
\text { Point }\end{array}$ & ALD & BAYT & $\begin{array}{l}\text { CÑO } \\
\text { x MAC }\end{array}$ \\
\hline \multirow[t]{4}{*}{1} & \multirow[t]{2}{*}{ COGENT } & shoot & 10.2 & 9.5 & 5.5 \\
\hline & & root & 28.6 & 16.3 & 8.9 \\
\hline & \multirow[t]{2}{*}{$\mathrm{mY3}$} & shoot & 10.0 & 11.5 & 12.6 \\
\hline & & root & 17.8 & 16.4 & 23.6 \\
\hline \multirow[t]{4}{*}{$2^{1}$} & \multirow[t]{2}{*}{ COGENT } & shoot & 21.4 & 20.1 & 11.7 \\
\hline & & root & 1,2 & 0,2 & 1,2 \\
\hline & \multirow[t]{2}{*}{$\mathrm{mY} 3$} & shoot & 24.8 & 25.2 & 22.9 \\
\hline & & root & 0,3 & 0,4 & 1,2 \\
\hline \multirow[t]{4}{*}{$3^{11}$} & \multirow[t]{2}{*}{ COGENT } & shoot & 43.3 & 30.3 & 27.0 \\
\hline & & root & 1,4 & 0,2 & 1,7 \\
\hline & \multirow[t]{2}{*}{$\mathrm{mY} 3$} & shoot & 42.2 & 42.3 & 44.6 \\
\hline & & root & 0,4 & 1,7 & 1,7 \\
\hline \multirow[t]{2}{*}{$4^{2}$} & COGENT & shoot & 59.6 & 67.8 & 52.7 \\
\hline & $\mathrm{mY3}$ & shoot & 104.1 & 90.6 & 133.0 \\
\hline \multirow[t]{2}{*}{$5^{2}$} & COGENT & shoot & 77.0 & 95.0 & 84.7 \\
\hline & $\mathrm{mY3}$ & shoot & 123.4 & 108.8 & 175.0 \\
\hline
\end{tabular}

$\longleftarrow$ Number of additional roots during the first subculture, first number ismean primary root while the second number is mean secondary roots

${ }^{24}$ Shoot length during the second subculture

growth among the three genotypes in COGENT. VMAC1 had the best growth in $\mathrm{mY} 3$ since the medium was developed to suit the need of the makapuno hybrids (Nuñez and de Paz, 1996).

\section{CONCLUSION AND RECOMMENDATION}

Results indicate that VSU-modified $\mathrm{mY} 3$ is more suitable than COGENT for the in vitro culture of embryos of the normal coconut types ALD and BAYT and the hybrid makapuno VMAC1. This was evidenced by significantly higher germination rates and better development of plantlets in the former medium. However, the specific factor(s) contributing to $\mathrm{m} Y 3$ 's suitability cannot be determined from the three variable parameters; vitamin components, iron concentration and state or phase of the medium. Said factors should be 
determined through further experimentation.

Slight variation in percentages of germination of the three coconut types showed genotypic differences in response to the germination medium but these were not significant. Obviously, since $\mathrm{mY} 3$ was tailored for the hybrid makapuno, this medium proved to be the best suited to VMACl.

\section{LITERATURE CITED}

DEL ROSARIO, A. G. 1997. Status of research on coconut embryo culture and acclimatization techniques in UPLB. Paper presented to evaluate the status of research on coconut embryo culture and identify research gaps. COGENT Workshop.

DUCHEFA. 1998. Catalogue 98-99. DUCHEFA Biochemie BV. A. Hofmanweg 71, 2031 BH Haarlem, The Netherlands. p.11.

EEUWENS, C. J. 1978. Effects of organic nutrients and hormones on growth and development of tissue explants from coconut (Cocos nucifera L.) and date (Phoenix dactylifera) palms cultured in vitro.Physiologica Plantarum 42:173178.

ENGELMANN, FLORENT. 1997. Current state of the art and problems with in vitro culture of coconut embryos. IPGRI, Via delle Sette Chiese 142, 00145 Rome, Italy. http//www.ipgri.cgiar.org/publications/HTMLPublications/363/ch2.htm

FRISON, E. A., C. A. J. PUTTER and M. DIEKMAN (editors). 1993. FAO/IBPGR Technical Guidelines for the Safe Movement of Coconut Germplasm. FAO/IBPGR Technical Guidelines for the Safe Movement of Germplasm. FAO/IBPGR, Rome.

IPGRI. 1998. Improvement of in vitro technique for collecting and exchange of coconut (Cocos nucifera L.) germplasm. Progress Report.

NUÑEZ, T. C. and V. M. DE PAZ. 1996. Development of new types of pure makapuno. The Philippine Journal of Coconut Studies 21(1):41-47.

RILLO, E. P. 1997. Makapuno embryo culture technology. In: Makapuno development and market trends (Seminar-Workshop Proceedings).Philippine Coconut Research and Development Foundation, Inc. pp.28-45.

RILLO, E. P. 2000. Second International Workshop on Coconut Embryo Culture. Coconut Embryo Culture Network Newsletter. 3(1) 1-3.

SAMONTE, J. L., MENDOZA, E. M. T., ILAG L. L., CRUZ, N. B. DE LA, and RAMIREZ, D. A. 1989. Galactomannan degrading enzymes in maturing normal and makapuno and germinating normal coconut endosperm. Phytochemistry 28(9):2269-2273. 